\title{
INTERAÇÕES E SOCIABILIDADES DIGITAIS NA SOCIEDADE INFORMACIONAL
}

\section{DIGITAL INTERACTIONS AND SOCITIES IN THE INFORMATION SOCIETY}

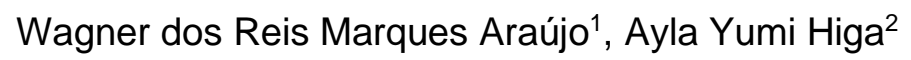 \\ 1 Universidade do Estado de Minas Gerais (UEMG), Unidade Carangola, Brasil, e-mail: \\ wagner.araujo@uemg.br. \\ 2 Universidade Estadual de Campinas (UNICAMP), Programa de Pós-Graduação em Artes Visuais, \\ Brasil, e-mail: aylahiga@hotmail.com.
}

ARTICLE INFO

Article history:

Received 2019-03-27

Accepted 2019-06-17

Available online 2019-06-17
Palavras-chave: Internet. Sociabilidades. Sociedade informacional. Redes Sociais.

Keywords: Internet. Socialities. Information society. Social networks.

RESUMO. Nos anos 2000 a internet se transformou em uma ferramenta inovadora e essencial para 0 sujeito na era da comunicação. O uso racional dessa ferramenta de comunicação proporciona descobertas e possibilidades de reformulações da subjetividade do Ser pós-moderno. Nesse sentido, esta discussão busca entender como os indivíduos se integraram à sociedade informacional, antes, porém, traçamos um breve histórico da Internet e da difusão das redes sociais enquanto espaços de sociabilidade e veiculação de informações. Em nossa análise, detemo-nos especialmente no o canal do YouTube "Felipe Neto: Não faz sentido", onde podemos observar o caso do Ser que se reinventa através de tecnologias digitais. Isso porque, conforme Castells (199), a revolução tecnológica e a transformação do social estão ligadas a penetrabilidade da informação por toda a estrutura social, dado ao grau de desenvolvimento das sociedades.

ABSTRACT. In the 2000s, the internet became an innovative and essential tool for the subject in the age of communication. The rational use of this communication tool provides discoveries and possibilities for reformulations of the subjectivity of the postmodern Being. In this sense, this discussion seeks to understand how individuals have integrated themselves into the information society, before, however, we trace a brief history of the Internet and the diffusion of social networks as spaces of sociability and information dissemination. In our analysis, we focus especially on the YouTube channel "Felipe Neto: It makes no sense", where we can observe the case of the Being that reinvents itself through digital technologies. This is because, according to Castells (199), the technological revolution and the transformation of the social are linked to the penetrability of information throughout the social structure, given the degree of development of societies.

\section{Introdução}

No momento atual, parece-nos óbvio que as profundas transformações da tecnologia da informação - do aparecimento da escrita à invenção da imprensa, ao advento da televisão, ao aparecimento das novas mídias - causaram transformações significativas sobre a sociedade. Não podemos ignorar que as informações se diluem com a mesma velocidade com que surgem tecnologias aplicadas às mídias comunicacionais.

Na obra, Estética da Comunicação: da consciência comunicativa ao "eu" digital, publicada em 2007, Luís Mauro Sá Martino analisa sob o enfoque da estética da 
comunicação, as várias formas de comunicação (arquitetura, Internet, televisão, literatura), delineando as relações entre mídia, indivíduo e a vida cotidiana. As análises do autor tomam como referência uma matriz teórica articulada às contribuições das ciências sociais com o universo das pesquisas em comunicação social.

No século 21 o ser humano se recria a partir da mídia de massa, atribuindo outros sentidos e significados aos aparatos tecnológicos. As pesquisas de Matino (2007) indicam, por um lado, que o movimento iniciado há aproximadamente um século com o cinema e a televisão atinge um grau inédito, no qual as pessoas têm a possibilidade de criar uma nova identidade individual nas mídias eletrônicas; esse fenômeno ocorre ao mesmo tempo em que o planeta se unifica quase a força no fluxo global de imagens e sentidos (MARTINO, 2007, p. 10).

Tal aspecto nos possibilita perceber a construção do "eu" digital no contexto do advento das novas tecnologias da informação e da comunicação. Muito antes disso, porém, com o surgimento do rádio e do cinema surge a expressão "comunicação de massa" criada para referir-se a esses objetos tecnológicos, já que a impressa prescindia de um público alfabetizado que não atingia as "massas".

Nos anos de 1960, com a obra The Gutenberg Galaxy (1962) Marshall McLuhan elabora o conceito "aldeia global" para referir-se às transformações sociais provocadas pela revolução tecnológica do computador e das telecomunicações. Na visão esse filósofo canadense, o progresso tecnológico estava reduzindo o planeta à mesma situação que ocorre em uma aldeia. Naquele contexto, Mcluhan (1962) afirma que as tecnologias da comunicação possibilitariam a interligação entre todas as regiões do globo, gerando uma teia de dependências mútuas, promovendo redes de solidariedade e lutas pelos mesmos ideais, como a economia e a ecologia em prol do desenvolvimento sustentável.

McLuhan (1962) elege como paradigma da "aldeia global" a televisão que se tornara um meio de comunicação de massa em nível internacional, integrando o mundo via satélite. Entusiasta desses objetos tecnológicos, o estudioso dos meios de comunicação ignorou que as formas de comunicação que permeiam uma aldeia são essencialmente bidirecionais, ocorrendo entre dois indivíduos por meio das relações intersubjetivas. De fato, foi há bem pouco tempo com o computador, os aparelhos de celular e a Internet que o conceito começou a se materializar.

O princípio que norteia este conceito é, portanto, o de um mundo interligado com estreitas relações econômicas, políticas, sociais e culturais, resultados do desenvolvimento das Tecnologias da Informação e da Comunicação (TIC), especialmente pelo surgimento da Word Wide Web diminuidor das distâncias globais. Nessa perspectiva, são apontadas três metáforas para compreender a sociedade contemporânea: o meio é a mensagem, o impacto sensorial e aldeia global. 


\section{Os meios de comunicação de massa: o Radio, a Televisão e a Internet}

No início do século XX, com a popularização dos jornais e o surgimento de novos meios de comunicação, como o rádio e o cinema os governos e grupos políticos perceberam a força de persuasão desses meios, principalmente do rádio. Nesse sentido, a difusão de novos meios de comunicação de massa foi, portanto, o limiar do fim da Galáxia de Gutenberg.

De acordo com Chauí (2010, p. 293), "a expressão comunicação de massa foi criada para referir-se aos objetos tecnológicos capazes de transmitir a mesma informação para um público muito amplo, isto é, para a massa". Sendo desse modo, a era da comunicação de massa inicia com a difusão do rádio, pois sua popularização deveu-se por suas possibilidades de alcance geográfico e, principalmente, por não prescindir de um receptor alfabetizado, era preciso apenas atenção e imaginação.

Inicialmente esse veículo de comunicação gerou muito interesse por parte dos aparelhos de estados por seu poder de convencimento e persuasão. Tal era seu poder de persuasão e convencimento sobre os ouvintes, que o nazismo o utilizou na Alemanha para difusão de propaganda ideológica e controle da informação durante a II Guerra Mundial.

Nos Estados Unidos da América, em 1938, a rede de rádio CBS interrompe sua programação para noticiar uma suposta invasão alienígena, tratava-se, porém, da transmissão do romance A guerra dos mundos, de George Wells, houve grande pânico devido a um mal-entendido: cerca de 6 milhões de pessoas sintonizaram no programa, sendo que metade delas sintonizou depois da introdução em que explicavam que não passava de uma peça de ficção, o caos paralisou três cidades.

Nos fins dos anos 1930, a surge a televisão que se popularizou somente após a Segunda Guerra mundial, graças aos avanços tecnológicos e o aumento do poder de consumo das pessoas. Nas décadas seguintes a televisão vai adquirindo o mesmo poder e força de convencimento que o rádio tinha anteriormente.

Conforme ilustra Castells (2009, p.418) "a modalidade de comunicação da televisão é um meio fundamentalmente novo caracterizado pela sua sedução, estimulação sensorial da realidade e fácil comunicabilidade, na linha do modelo do menor esforço psicológico". Diferente do rádio, as imagens televisivas passam a preencher a necessidade que o telespectador tinha em trabalhar a imaginação. Não era necessário que o mesmo fizesse uma reflexão ou uma critica do que estava sendo transmitido, o que o tornava receptor passivo e acrítico.

Diante do que foi posto pode-se, portanto, afirmar que tanto a televisão como o rádio são, seguramente, os meios de comunicação de massa que têm grande impacto sobre os espectadores no contexto da aldeia global. Tais meios contribuem para a formação de opinião dos seus usuários. Entretanto, essa comunicação "era um mundo de comunicação de mão única, não de interação" (CASTELLS, 2009, p. 427). Todavia esse cenário vai se 
modificando com a inserção e a difusão do uso da Internet que traz para televisão uma forma de ser ter um retorno da audiência em relação a sua programação.

Isso porque é possível por meio da internet obter informações se o telespectador está ou não acompanhando a mesma ou se está tendo boa receptividade em relação ao que está sendo veiculado. Nos anos de 1960 foram iniciadas entre os militares norte-americanos as primeiras pesquisas que viriam a dar origem a Internet.

Naquele período o mundo estava polarizado entre dois blocos ideológicos e politicamente antagônicos, qualquer mecanismo, qualquer inovação tecnológica ou ferramenta nova poderia favorecer a disputa liderada pela União Soviética (URSS) e pelos Estados Unidos (USA). Sua origem pode ser encontrada na Arpanet, redes (conjuntos de nós interconectados) de computadores montada pela Advanced Research Projects Agency ARPA.

A ARPA foi formada em 1958 pelo Departamento de Defesa dos Estados Unidos, com a missão de mobilizar recursos de pesquisas e com o objetivo de alcançar superioridade tecnológica militar em relação a URSS na esteira do lançamento do primeiro Sputnik, em 1957 (CASTELLS, 2003). Entretanto, foi somente a partir de 1995 que o uso da Internet alcançou níveis mundiais com mais de 16 milhões de usuários.

No livro A Galáxia Internet: reflexões sobre Internet, negócios e sociedade, Manuel Castells (2003) oferece uma interessante análise do desenvolvimento de uma nova sociedade baseada na lógica da Internet. Segundo esse mesmo autor, a tecnologia da informação significa hoje tudo que a eletricidade foi na Era Industrial, ou muito mais, sua capacidade de chegar a todos os lugares é tão rápida quanto à chegada da eletricidade. Iniciada, então, a "Galáxia da Internet" as pessoas passam a usá-la como sistema de comunicação e forma de organização.

Nestes termos postos, portanto, pode-se afirmar que "a internet é um meio de comunicação que permite, pela primeira vez, a comunicação de muitos com muitos, num momento escolhido, em escala global" (CASTELLS, 2001, p. 8). Tais características contribuíram para a Internet tornar-se a base tecnológica para a forma organizacional da "era da Informação". Além disso, ela vem tornando-se a principal rede distribuidora de informações, sendo, portanto, um meio de comunicação que pela primeira vez permite a comunicação de muitos com muitos.

No que diz respeito a aspectos econômicos, a essência do negócio eletrônico está na conexão em rede, interativa, baseada na Internet, entre produtores, consumidores e prestadores de serviços, com capacidade de interagir. Os usos da internet são esmagadores instrumentais ligados a trabalho, família e a vida cotidiana (CASTELLS, 2003). Um dos adventos tecnológicos que nasce na era da internet é o Website YouTube. 


\section{As Redes Sociais: YouTube e o WebSite}

O YouTube foi fundado em fevereiro de 2005 nos Estados Unidos da América por Chad Hurley, Steve Chen e Jawed Karim. Essa ferramenta tecnológica consiste em um Website que possui uma interface simples através da qual o usuário pode fazer o upload de seus conteúdos, compartilhá-los e/ou assistir a outros vídeos em streaming ${ }^{1}$ sem a necessidade de ter um alto nível de conhecimento tecnológico. De certa forma, o seu acesso é democrático para aqueles/las que têm acesso à Internet.

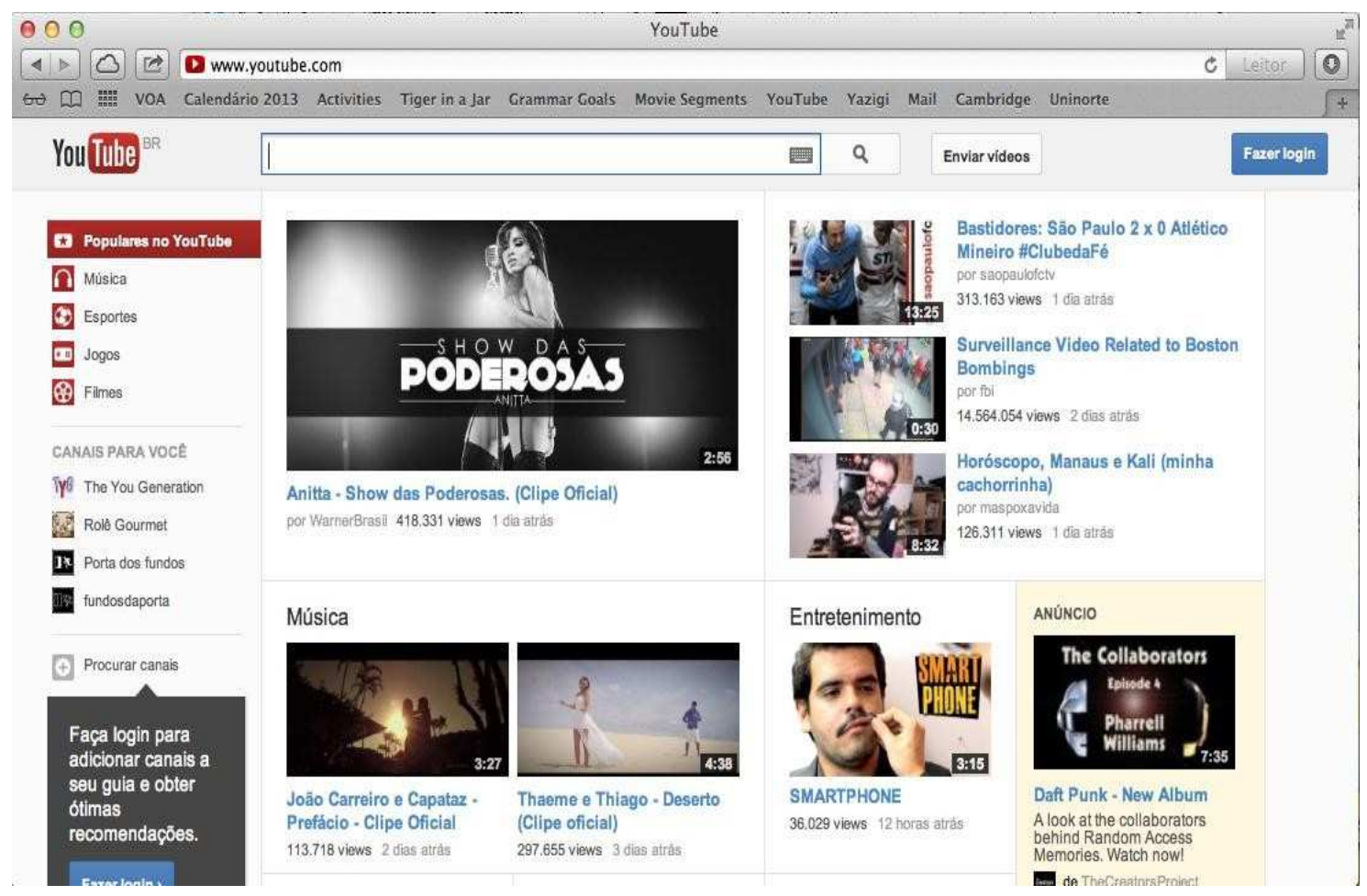

Figura 1: $O$ site Youtube

Fonte: http://www.youtube.com (2010)

Nesse sentido, o YouTube não estabelece limites para o número de vídeos que cada usuário pode colocar em seu canal. Entre as suas ferramentas que ele oferece, estão as funções básicas de comunidade que possibilita os usuários a se conectarem com outras pessoas. Além disso, gera URLS e códigos HTML permitindo que seus vídeos possam ser incorporados em outros sites ou redes sociais, como Blogs, Facebook, Twitter, entre outras redes sociais. Conforme Weinberger (2007, p. 224), o YouTube é uma "nova categoria de negócio que aumenta o valor da informação desenvolvida em outro lugar e posteriormente beneficia os criadores originais dessa informação".

1 Streaming (palavra em inglês) ou fluxo de mídia é uma forma de distribuir informação multimídia numa rede através de pacotes, esse meio digital é frequentemente utilizado para distribuir conteúdo multimídia através da Internet. 
Os vídeos postados que possuem grande quantidade de acesso ganham visibilidade e passam a ter propagandas anexadas ao seu vídeo. O usuário que desejar assistir aos vídeos que tiverem muitas visualizações, obrigatoriamente, terá que assistir conteúdo publicitário de 30 segundos, caso contrário, deverá esperar um tempo mínimo para que possa pular o anúncio anexado.

Burguess e Green (2009, p. 45) apontam os benefícios trazidos pelo YouTube para seus participantes:

O sinalizador do sucesso dessas formas é medido paradoxalmente não apenas por sua popularidade on-line, mas por sua habilidade subsequente em atravessar os mecanismos de contenção da velha mídia - o contrato de gravação, o festival de cinema, o piloto de televisão, a campanha de publicidade (BURGUESS; GREEN, 2009, p. 45)

O YouTube sempre trabalhou com compartilhamento de vídeos com conteúdo amador. Com o seu crescimento e o aumento de popularidade que esses meios alçaram nos últimos anos, essa ferramenta passou a ser utilizada por grandes empresas que trabalham com vídeos em alta qualidade e para fins específicos. Em um primeiro momento, Website era um portal que oferecia aos seus usuários e participantes comuns, a oportunidade de mostrarem a si mesmos, de encontrarem certa forma visibilidade na rede.

Ainda, outro aspecto do Youtube é a possibilidade de interação entre o usuário, o criador do vídeo de um canal no Youtube e os usuários que assistem as suas postagens. Tal interação e feita pela caixa de comentários que pode estar disponível ou não, dependendo do dono do canal. Essa possível interação caracteriza o Youtube como um site de cultura participativa, segundo a definição de Jenkins (2006, p. 290), a cultura participativa estabelece que "os fãs e outro consumidores são convidados a participar ativamente da criação e circulação do novo conteúdo".

De igual modo, a cultura participativa resulta na valorização da mídia amadora e comunitária, trazendo "ideias otimistas sobre a democratização da produção cultural" (BURGUESS; GREEN, 2009, p. 31). Diante do que foi posto acima, formulamos as seguintes questões: Quem são esses usuários do Youtube? Como é o ser nessa nova era? Se o mundo vem sofrendo transformações e se adaptando com as mudanças tecnológicas, o que podemos dizer sobre o Ser frente às novas mídias.

Segundo a definição do dicionário Priberam: 2. Sujeito, pessoa; 3. Ser humano; 5. organismo único pertencente a um grupo. No contexto da "Galáxia da Internet", o Ser vem se reconstruindo paralelamente. A cada fase, a cada descoberta, ele se refaz de acordo com as novas peculiaridades. Martino (2007) explica que:

No século XXI, o ser humano se recria a partir da mídia. O movimento iniciado há um século com o cinema e a televisão atinge um grau inédito, no qual as pessoas 
têm a possibilidade de criar uma nova identidade individual nas mídias eletrônicas, ao mesmo tempo em que o planeta se unifica quase à força no fluxo global de imagens e sentidos (2007, p. 9).

A internet traz um novo contexto onde é possível se comunicar através da linguagem escrita e oral por meio de aparatos audiovisuais, ampliando as relações intersubjetivas. É o resultado da soma de vários modos de comunicação em uma rede interativa. Seu alcance pode chegar ao outro lado do mundo.

Segundo Castells (1999, p. 414), foi "o surgimento de um novo sistema eletrônico de comunicação caracterizado pelo seu alcance global, integração de todos os meios de comunicação e interatividade potencial está mudando e mudará sempre nossa cultura". Uma de suas características é que ele tem a capacidade de captar a maioria das expressões culturais, diferente da televisão, a grande quantidade de conteúdo, produzido por qualquer pessoa no ambiente online, permite que muitas expressões culturais sejam integradas a essa rede. Nesse sentido, Castells (1999) afirma que:

As mensagens não são apenas segmentadas pelos mercados mediante as estratégias do emissor, mas também são cada vez mais diversificadas pelos usuários da mídia de acordo com seus interesses, por intermédio da exploração das vantagens das capacidades interativas (1999, p. 457).

Nesse novo espaço virtual, o Ser tem a possibilidade de criar seu próprio conteúdo, tendo a oportunidade de se construir da maneira que desejar. E é dentro desse espaço virtual que o YouTube nasce, com sua cultura participativa e a chance de qualquer ser, se tornar famoso e com ele surgem os vlogs que, de acordo com Burgess e Green (2009, p, 50) o "padrão de vlog - alguém falando diretamente para a câmera".

Nesse sentido, os vlogs possuem uma característica confessional por se concentram na observação da vida cotidiana e não possuem grande conhecimento tecnológico, muito menos exigem aparatos tecnológicos de alto custo, é preciso apenas com uma Webcam e um pequeno conhecimento de edição (muitas vezes não é necessário se fazer edição), pois é possível produzir seu próprio vídeo.

O YouTub incorpora nas suas características, o estilo dos vídeos produzidos para vlogs remetendo o usuário à comunicação cara a cara, simultaneamente, que se diferenciará do vídeo on-line e da televisão. Segundo Burgess e Green (2009, p. 79): "parece que, mais do que qualquer outro formato na amostragem, o vlog como gênero de comunicação convida à critica, ao debate e à discussão. A resposta direta, por meio de comentários ou de vídeos, é o ponto central desse modo de envolvimento".

Essa abordagem direta e persistente convida o espectador a ter uma reação. Para melhor visualizarmos essas características, analisamos o canal do Youtuber "Felipe Neto: não faz sentido", que se encaixa na categoria de vlog. Esse vlog criado por Felipe Neto, de 
25 anos, existe desde o ano de 2010. Possui mais de dois milhões de pessoas inscritas e já obteve mais de 160 milhões de visualizações.

Os vídeos postados pelo internauta se tornaram um grande sucesso na Internet, quanto mais inscritos mais visualizações ganhavam. Sua popularidade chegou a um nível que ultrapassou as barreiras do mundo virtual, Felipe começou a participar de campanhas publicitárias e se tornou garoto-propaganda de algumas marcas para o seguimento jovem.

No ano de 2011, oito meses após seu sucesso no Youtube, ele estreia no canal Multishow com o programa "Será que faz sentido?" e, também, em um quadro no programa Esporte Espetacular, veiculado pela Rede Globo de Televisão. Em julho do mesmo ano, o jovem inicia um novo programa "Até que faz sentidos".

Burgess e Green (2009) explicam que: "A promessa de Youtubers talentosos, mas não descobertos podem saltar de seus mundos „mundos comuns" para o genuíno mundo da mídia" está profundamente enraizada no Youtube em si” (2009, p. 44). Nestes termos, os vídeos, além de abordarem temas da atualidade, fazem criticas a comportamentos de famosos e até mesmo da população.

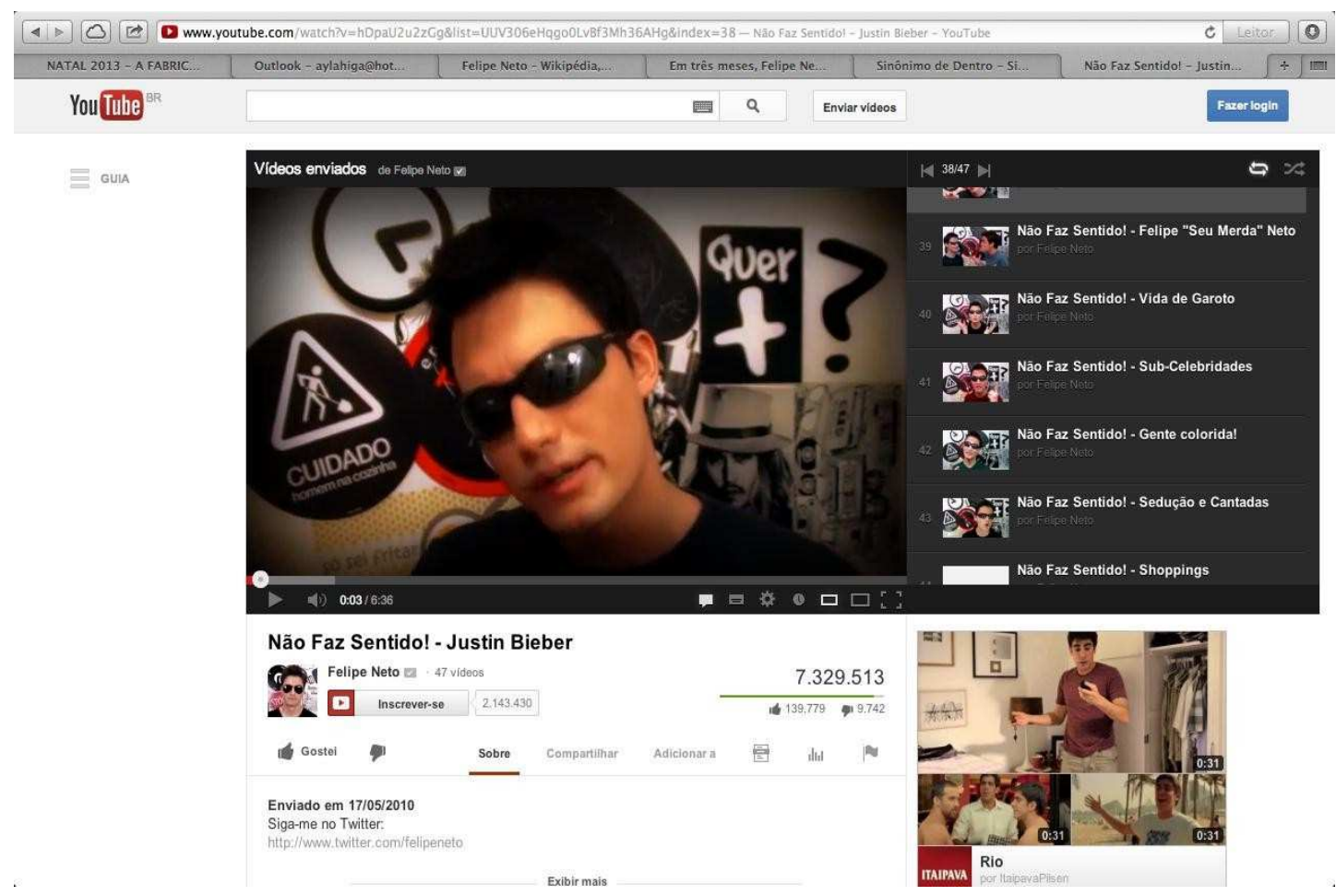

Figura 2: O site Youtube

Fonte: http://www.youtube.com (2010)

$\mathrm{Na}$ imagem acima (figura 2) podemos perceber as características que o definem como um vlog. Apenas uma pessoa falando com uma câmera, possui um tom confessional, pois Felipe neste vídeo, expressa sua opinião sobre o cantor Justin Bieber. Isso produz uma 
reação nos espectadores, que sentem a necessidade de comentar sobre o que foi exposto. Podemos visualizar essa troca de informação e opinião nos comentários do mesmo vídeo

E é por meio dessa interação que a maioria dos vlogs monta seus conteúdos e reconstroem seus perfis e segundo Martino (2007):

O indivíduo se define a partir de suas relações de comunicação, em sua sensibilidade (aisthesis) para organizar e reorganizar os fluxos contínuos de mensagens e se definir em relação a eles, bem como aos outros indivíduos, em uma seleção dos eventos comunicativos, dos signos, das mensagens ( MARTINO, 2007, p. 9).

Analisando a trajetória de seus temas postados durante o ano de 2011, ele postou um vídeo sobre o cantor e ator Fiuk ${ }^{2}$, que naquele momento estava na mídia atuando em uma novela da Rede Globo. Em 2012 ele fez um vídeo sobre o filme Amanhecer 6, o último episódio da saga Crepúsculo no mesmo ano de estreia do filme.

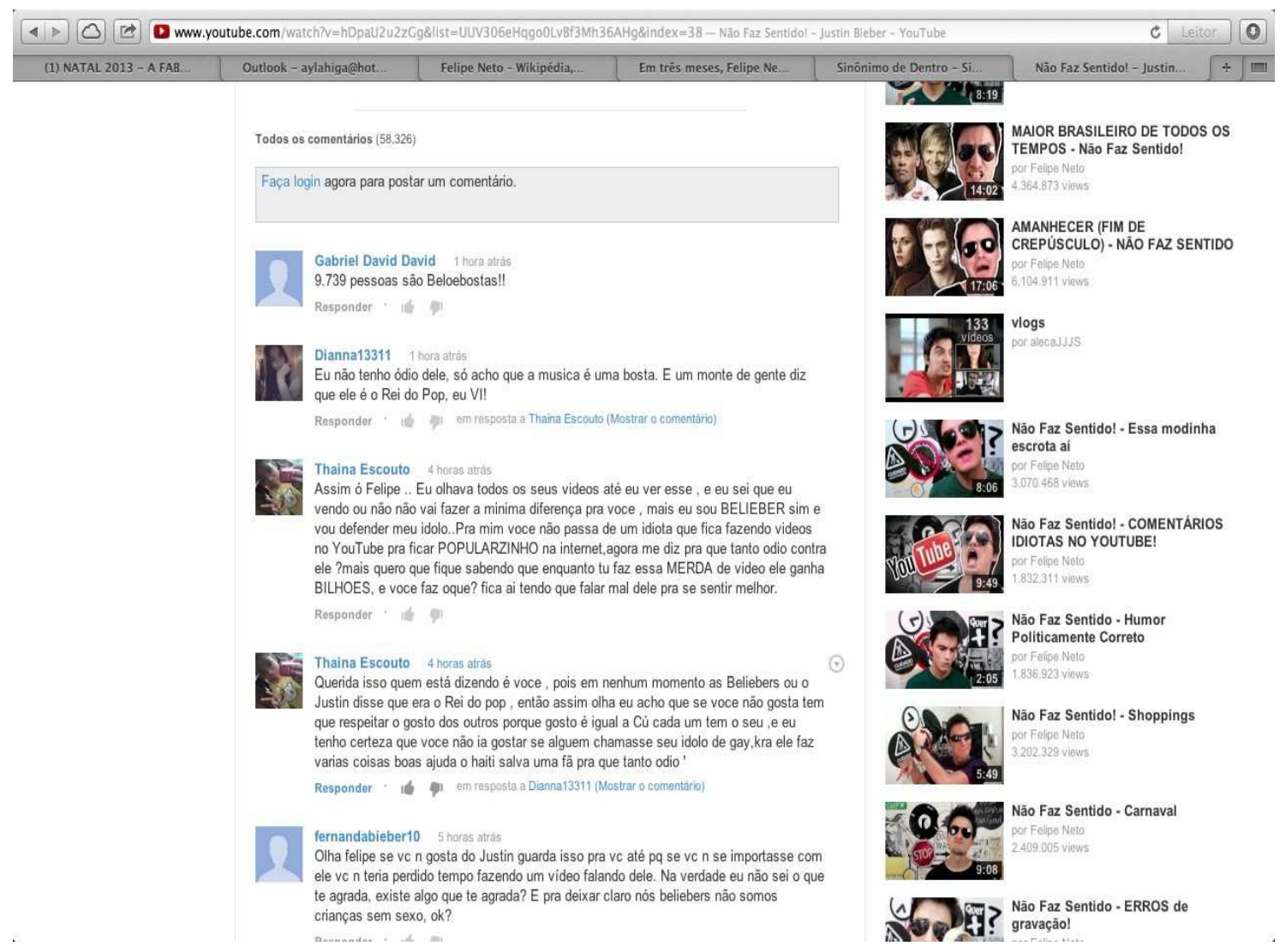

Figura 3: O site Youtube/2010

Fonte: http://www.youtube.com

Nesse sentido, Felipe sempre traz temas da atualidade o que resulta em grande repercussão, produzindo 50 vídeo Não faz sentido! - Fiukar obteve mais de 32.000

${ }^{2}$ O vídeo Não faz sentido! Fiukar obteve mais de 32.000 comentários e 5 milhões de visualizações. 
comentários e 5 milhões de visualizações. 6 O vídeo Não faz sentido - Amanhecer ${ }^{3}$ (Fim de Crepúsculo) obteve mais de 72 mil comentários e 6 milhões de visualizações diferentes reações nos espectadores eliminando, de certa forma, a solidão comunicativa da consciência.

Segundo Silva (2011): "ela acontece quando tentamos compartilhar os signos, mas o outro desconhece os códigos e assim não consegue decifrá-los. Essa solidão é um dos fatores que produz espaços de silencio na comunicação" (2011, p. 3). A criação de um perfil virtual, ou seja, uma identidade digital que permite ao usuário decidir que informações quer disponibilizar, quais postagem deseja comentar. Entretanto esse conteúdo pode se modificar de acordo com as transformações do mundo real e acompanhar suas mudanças e, portanto, deixar de pertencer àquele contexto.

\section{Considerações Finais}

Nessa pesquisa podemos constatar que a internet traz consigo novas formas de sociabilidade e uma nova forma de vida, adaptada ao novo ambiente tecnológico. E o ser na era informacional, tem o poder de se recriar e se refazer como desejar. Os aparatos digitais e a realidade virtual permitem a ele essa reconstrução. Segundo, Martino (2007, p.179), "a construção do 'eu' digital é uma das principais alterações no cotidiano feitas pela internet”.

No espaço virtual, "qualquer ser humano é livre para se reinventar-se a si próprio conforme seu gosto" (2007, p.179). Um das razões para a autonomia do usuário é o resultado da interatividade que permite às pessoas conectadas à rede estabelecerem formas de comunicação. Uma modalidade de interação onde há trocas de signos e significados os quais possibilitam os mesmo a se construírem de acordo com o que está acontecendo nos mundos real e virtual, para que não deixem de existir na rede.

Conforme constatamos, casos como o de Felipe Neto, demonstram que essas relações, essa reconfiguração do Ser pode ultrapassar o espaço da Internet, essas ações podem ter resultados e consequências reais.à vista disso, o usuário se torna livre para ser o que desejar, porém, as consequências de suas ações podem ultrapassar os limites virtuais.

\footnotetext{
${ }^{3}$ O vídeo Não faz sentido! Amanhecer (Fim de Crepúsculo) obteve mais de 72 mil comentários e seis milhões de visualizações.
} 


\section{REFERÊNCIAS}

BURGESS, Jean; GREEN, Joshua. Youtube e a revolução digital. São Paulo. Editora Aleph, 2009.

CASTELLS, Manuel. A galáxia da internet: Reflexões sobre a internet, os negócios e a sociedade (tradução, Brasil), Rio de Janeiro: Jorge Zahar Ed., 2003.

A Era da Informação: economia, sociedade e cultura. V. 2/ 6. ed.; tradução de Klauss Brandinni Gerhardt. (Sindicato Nacional dos Editores de Livros, RJ, Brasil) São Paulo: Paz e Terra, 1999.

JENKINS, Henry. Cultura da Convergência. Trad. Susana Alexandria. São Paulo: Aleph, 2008.

MARTINO, Luís Mauro. Estética da Comunicação: Da consciência comunicativa ao "eu" digital. Petrópolis: Rio de Janeiro. Editora Vozes, 2007. CHAUI, Marilena. Convite à Filosofia. São Paulo. Editora Ática, 2010.

MCLUHAN, Marshall. Os meios de comunicação como extensões do homem. São Paulo: Cultrix, 1969.

\& FIORE, Quentin. Guerra e paz na aldeia global. Rio de Janeiro: Record, 1971.

SILVA, Danielle Vieire da; Resenha Estética da comunicação: da consciência comunicativa ao "eu” digital (MARTINO, Luís Mauro Sá. Petrópolis, RJ: Vozes, 2007). Revista Temática. Paraíba: Ano VII, n.05, Maio. 2011, pp. 1- 6. 